\title{
Medical Image of the Week: Pulmonary Metastases of Rectal Cancer
}

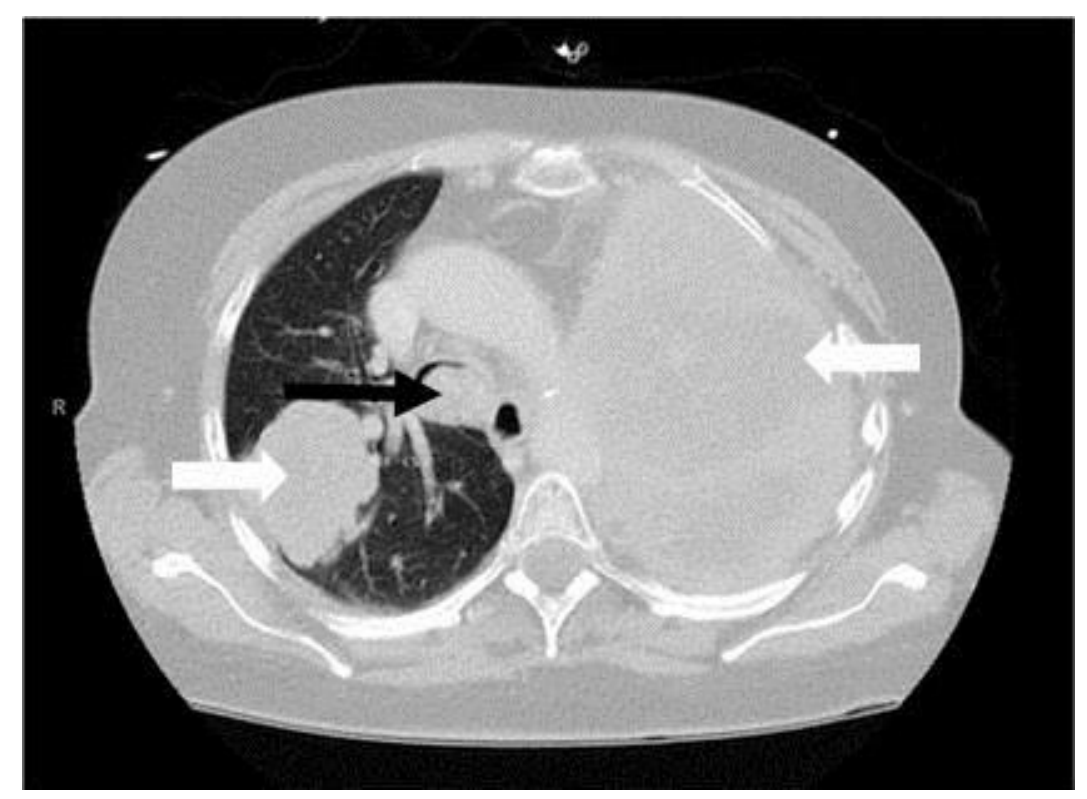

Figure 1. CT scan of the chest shows bilateral masses (white arrows), left sided pleural effusion and endobronchial mass (black arrow).

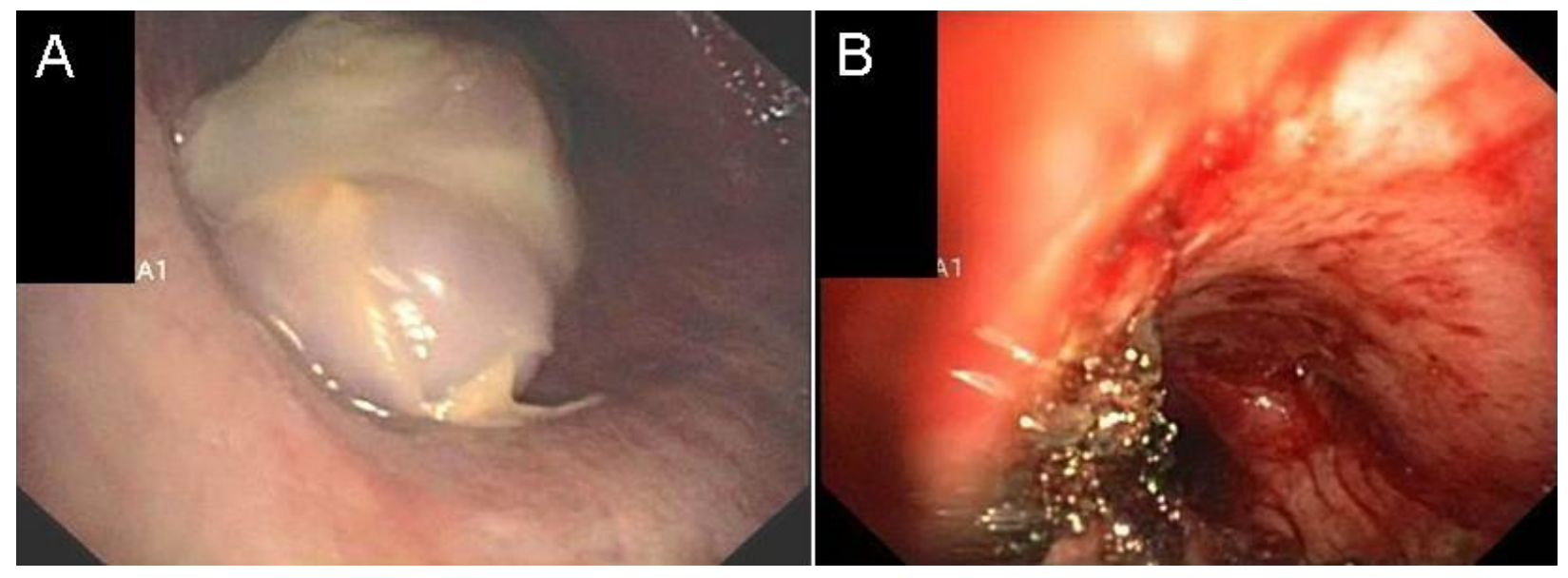

Figure 2: Endobronchial mass $(A)$ before and $(B)$ after removal.

A 51-year-old woman with known rectal cancer currently receiving systemic chemotherapy presented with 2 weeks of worsening dyspnea on exertion. The day prior to admission she developed persistent inspiratory and expiratory wheeze. CT scan demonstrated right main stem endobronchial mass and a heterogeneous mass comprising the entire left hemithorax (Figure 1). Flexible bronchoscopy demonstrated a fungating mass at the carina extending down both main stems (Figure 2). The mass 
was snared and removed with cryotherapy and pathology was consistent with metastatic rectal adenocarcinoma.

Michael Insel MD, Naser Mahmoud MD and Afshin Sam MD

Division of Pulmonary, Allergy, Critical Care and Sleep

Banner-University Medical Center Tucson

Tucson, AZ USA 